\title{
GPR30 regulates the EGFR-Akt cascade and predicts lower survival in patients with ovarian cancer
}

Satoe Fujiwara, Yoshito Terai, , Hiroshi Kawaguchi, Masaaki Takai, Saha Yoo, Yoshimichi Tanaka, Tomohito Tanaka, Satoshi Tsunetoh, Hiroshi Sasaki, Masanori Kanemura, Akiko Tanabe, Yoshiki Yamashita and Masahide Ohmichi

\begin{abstract}
Objectives: G protein-coupled receptor 30 (GPR30) is a 7-transmembrane estrogen receptor that functions alongside traditional estrogen receptors to regulate the cellular responses to estrogen. Recent studies suggest that GPR30 expression is associated with a poor prognosis, and that this is due to the GPR30-mediated transactivation of the EGFR in breast cancer. However, the biological contribution of GPR30 in ovarian cancer remains unclear. The purpose of this study was to elucidate the relationships between GPR30 expression and the clinicopathological findings, and to determine how the signaling cascade influences the prognosis of ovarian cancer.

Methods: The expression levels of GPR30, EGFR, ERa, and ER $\beta$ were analyzed using an immunohistochemical analysis, and their correlations with the clinicopathological features were examined in 10 patients with borderline malignant tumors and 152 patients with epithelial ovarian cancer. We also examined whether GPR30 signaling activates the EGFR-Akt pathway in an ovarian cancer cell line (Caov-3) by a Western blotting analysis.

Results: The GPR30 expression in ovarian carcinomas was significantly higher than that in borderline malignancies ( $p=0.0016)$, and was not associated with the expression of the EGFR, ERa, or ERß. The expression of GPR30 in clear cell carcinomas was significantly lower than that in other subtypes of cancer $(P<0.001)$. The expression of both GPR30 and EGFR was significantly associated with a poor prognosis in terms of the progression-free survival rate. The phosphorylation of the EGFR and Akt could be significantly enhanced by G1 ( $p<0.05)$ and inhibited by a Src family kinase inhibitor.

Conclusion: The expression of both GPR30 and EGFR is associated with a poor outcome in ovarian cancer, and GPR30 increases the phosphorylation of Akt via the EGFR in ovarian cancer cells. The regulation of GPR30 might be a potentially useful new therapeutic target in ovarian cancer.
\end{abstract}

Keywords: G protein-coupled receptor 30, GPR30, 7-transmembrane estrogen receptor, EGFR, Akt, ERa; Clear cell carcinomas, Prognostic factor

\section{Introduction}

Ovarian cancer is the most common cause of gynecological cancer-related death. Approximately $70 \%$ of all patients with ovarian cancer are diagnosed at an advanced stage, and $60 \%$ to $80 \%$ of patients die of the disease [1]. The main reasons for the poor prognosis are the high recurrence rate and resistance to second-line chemotherapeutics. Therefore, the development of new

\footnotetext{
* Correspondence: y-terai@poh.osaka-med.ac.jp

Department of Obstetrics and Gynecology, Osaka Medical College, 2-7, Daigaku-machi, Takatsuki, Osaka 569-8686, Japan
}

therapies is critical for the treatment of ovarian cancer patients.

Estrogens are major regulators of growth and differentiation in the normal ovaries, and also play an important role in the progression of ovarian cancer. Likewise, a marked proliferative response to estrogens was shown in ovarian surface epithelial cells, which are the site of $90 \%$ of malignancies [2], and an increased risk of ovarian tumors was observed in postmenopausal patients receiving estrogen replacement therapy [3-5]. The biological effects of estrogens are classically mediated by the

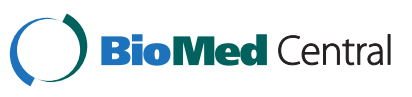


estrogen receptors $(E R) \alpha$, and $E R \beta$, which function as hormone-inducible transcription factors that bind to the estrogen-responsive elements (EREs) located within the promoter regions of target genes [6]. Moreover, it has been suggested that the nongenomic actions of estrogens, as well as the genomic effects, are susceptible to interference from environment estrogens [7]. However, the precise identity and function of many steroid membrane receptors are still controversial in terms of their specific molecular interactions with endogenous and environmental estrogens. Many studies have demonstrated that ER $\beta$ is highly represented in normal ovarian epithelial cells and benign tumors, whereas $\mathrm{ER} \alpha$ is the main form expressed in ovarian cancer [8-11]. The ER $\beta$ mRNA expression is inversely correlated with tumor progression, while the ER $\alpha$ mRNA expression is positively correlated with the progression $[10,12]$. The ER $\alpha /$ $\beta$ mRNA ratio is markedly increased in ovarian cancer [9]. In contrast with breast cancer, the prognostic value of the ER $\alpha$ or ER $\beta$ status, as well as the prediction of the responsiveness to anti-estrogen treatment, have not been clearly established for ovarian cancer [3-15].

The G protein-coupled receptor 30 (GPR30), which mediates the nongenomic signaling of 17-beta-estradiol (E2), is widely expressed in cancer cell lines and primary malignant tumors of the breast, endometrium, prostate and lungs [16,17], and is strongly associated with the proliferation, invasion, metastasis, and drug resistance of various cancer cell lines [18-24]. GPR30 protein expression correlates with the clinical and pathological biomarkers of a poor outcome in breast cancer and endometrial cancer $[25,26]$. Recent studies have shown that GPR30 exerts its effects through the activation of the epidermal growth factor receptor (EGFR) transduction pathway in endometrial cancer, breast cancer, and thyroid cancer cells [19,20,27-29]. Moreover, Filardo et al. found that estrogen rapidly activated extracellular signal-related kinase (ERK) 1/2 via EGFR transactivation in breast cancer cell lines, regardless of their ER status [20]. Signaling via the EGFR leads to multiple downstream events; for example, activation of phospholipase C (PLC), the phosphatidylinositol-3 kinase (PI3K)/Akt pathway and MAPK. The EGFR is reported to be present in 33-75\% [30] of ovarian cancers and has been implicated in both the growth and progression of this disease [31]. Akt activation is closely related to cancer cell growth, because it affects cancer cell survival, proliferation (leading to an increased cell number) and growth (increasing the cell size) [32-34].

Only one previous study has shown that high levels of GPR30 expression predict a poor prognosis in ovarian cancer [35]. This is not yet sufficient evidence of a role of GPR30 in ovarian cancer. Therefore, it was necessary to clarify whether GPR30 and the GPR30-dependent activation of MAPK-ERK1/2 via EGFR transactivation is important in ovarian cancer. In the current study, we evaluated the relationship between GPR30 expression and patient clinicopathological factors by immunohistochemistry in ovarian cancer specimens, and evaluated whether GPR30 mediates Akt activation via the EGFR, leading to a poor prognosis for ovarian cancer patients.

\section{Materials and methods \\ Patients}

This study was reviewed and approved by the Institutional Review Board of the Osaka Medical College and informed consent was obtained from all patients. The study included 162 patients with either primary epithelial ovarian cancer (152) or low malignant potential tumors [10] who underwent a diagnosis and surgical resection in the Department of Gynecology of Osaka Medical College Hospital in Japan between 2001 and 2009. In the 162 epithelial ovarian cancer and borderline malignant patients, an effort was made to perform optimal surgical cytoreduction and adequate staging, which included at least a total abdominal hysterectomy with bilateral salpingo-oophorectomy, omentectomy, peritoneal washings and retroperitoneal lymphadenectomy. The histology of all tumors was determined by a gynecological pathologist according to the WHO criteria (World Health Organization).

\section{Immunohistochemistry}

Five-micron sections from tumor tissues, which were formalin-fixed and embedded in paraffin, were prepared for the immunohistochemical analyses. The expression of GPR30 was analyzed as follows: Tumor sections were incubated at $4^{\circ} \mathrm{C}$ for $18 \mathrm{~h}$ with a GPR30-specific antibody, a rabbit polyclonal affinity-purified antibody directed against the C-terminal of GPR30, at a 1:50 dilution (LifeSpan BioSciences, Inc.). The EGFR expression was analyzed using the EGFR Pharm Dx kit (Dako Cytomation). The expression levels of ER $\alpha$ and ER $\beta$ were analyzed using a Dako Cytomation ER Pharm assay.

The interpretation of the immunohistochemical staining results was performed by two independent gynecological oncologists (who were accustomed to diagnosing gynecological malignancies) who were blinded to the clinicopathological data. For each core, the staining intensity (graded considering 0 as negative, $1+$ as weak, $2+$ as moderate, and $3+$ as strong) and the percentage of cells staining positive $(0-100 \%)$ were determined. The overexpression of GPR30 and the EGFR was defined to exist if $50 \%$ or more of the tumor cells exhibited cytoplasmic or membranous staining with a staining intensity of $2+$ or more. The overexpression of $E R \alpha$ and ER $\beta$ was defined to exist if $1 \%$ or more of the tumor cells exhibited nuclear staining with a staining intensity of $1+$ or more. 


\section{Cell culture}

One human ovarian mucinous adenocarcinoma cancer cell line, Caov-3, which was obtained from the American Type Culture Collection (Rockville, MD, USA), was grown in phenol red free DMEM containing 10\% dextran-coated, charcoal-treated fetal calf serum, 100 units/ $\mathrm{ml}$ penicillin, and $100 \mu \mathrm{g} / \mathrm{ml}$ streptomycin in a humidified atmosphere of $5 \% \mathrm{CO}_{2}$ with $95 \%$ air at $37^{\circ} \mathrm{C}$.

\section{Expression plasmids and cDNA transfection}

To make the pcDNA3.1-GPR30 expression construct, the cDNA of the full length GPR30 was amplified by PCR using a human mammary gland cDNA library as the template. For the transfection of each sample, oligomer-Lipofectamine plus complexes were prepared as follows: $100 \mathrm{pmol}$ of cDNA oligomer were diluted in $250 \mu \mathrm{l}$ of Opti-MEM (Invitrogen). The Lipofectamine plus was mixed gently before use, and then a $5 \mu \mathrm{l}$ aliquot was diluted in $250 \mu \mathrm{l}$ of Opti-MEM, mixed gently, and incubated for $5 \mathrm{~min}$ at room temperature. After the 5 min incubation, the diluted oligomer was combined with the diluted Lipofectamine plus, mixed gently, and incubated for another $20 \mathrm{~min}$ at room temperature. The oligomer-Lipofectamine plus complexes were added to each well containing cells and medium, and mixed gently by rocking the plate back and forth. The cells were incubated at $37^{\circ} \mathrm{C}$ in a $\mathrm{CO}_{2}$ incubator for $24 \mathrm{~h}$, then the cells were prepared for each assay.

\section{Proliferation assay}

After the seeding, the test cells were incubated with phenol red free DMEM containing 10\% dextran-coated, charcoal-treated fetal calf serum for 24 hours in 96 well plates. The changes in cell proliferation were examined by the addition of G1, which is a selective agonist of GPR30, or G15, which is a selective antagonist, with serum free DMEM for 48 hours. The number of Caov-3 cells after 48 hours of stimulation was determined by measuring the dissolved formazan products after the addition of MTS. All experiments were carried out in quadruplicate, and the cell viability was expressed as the ratio of the number of viable cells with G1 stimulation to that of cells without stimulation.

\section{Western blot analysis}

The cells were serum-starved and stimulated with PBS (phosphate-buffered saline) or $100 \mathrm{nM} \mathrm{G1}$ for $5 \mathrm{~min}$ or $15 \mathrm{~min}$. Cells were then washed twice in ice-cold PBS and lysed, and the cytoplasmic and nuclear fractions were separated using a Nuclear Extract Kit (Active Motif, Carlsbad, CA, USA). To detect all of the proteins, equal amounts of cytoplasmic proteins were separated by SDS-polyacrylamide gel electrophoresis and transferred to nitrocellulose membranes. Blocking was done in $10 \%$ bovine serum albumin in $1 \mathrm{x}$ Tris-buffered saline. The Western blot analyses were performed with various specific antibodies. The immunoreactive bands in the immunoblots were visualized with horseradish peroxidase-coupled goat anti-rabbit immunoglobulin using an enhanced chemiluminescence Western blotting system (ECL Plus, GE healthcare Life Sciences, Pittsburgh, PA, USA). All Western blots were checked for equal protein loading using Ponceau staining.

\section{Statistical analysis}

The statistical analyses in this study were carried out with the Stat View statistical software package (SAS Institute, Cary, NC, USA). Fisher's exact probably test was used to evaluate the correlations between the immunohistochemical and clinical data. The endpoints investigated were the progression-free survival and overall survival. The progression-free survival was defined as the time from the first day of chemotherapy until disease progression (based on the findings of imaging studies). Overall survival was defined as the time from the first day of chemotherapy to death from any cause. The univariate and multivariate analyses of the histology, progression-free survival and overall survival were determined with the Kaplan-Meier method using the log-rank test and the Cox proportional hazards model, respectively. Differences with p-values $<0.05$ were considered to be statistically significant.

\section{Results}

\section{Correlations of GPR30, EGFR, ERa and ER $\beta$ with the} clinicopathological features of ovarian carcinomas

The clinical and pathological data for the patients are shown in Table 1. Of the 162 investigated patients, 10, $39,14,77$ and 22 were categorized to have a borderline malignancy, and stage I, II, III and IV ovarian cancer, respectively. Of the 162 cases, 10 were borderline malignant tumors, 61 were histologically diagnosed to be serous adenocarcinoma, 30 endometrioid adenocarcinoma, 19 mucinous adenocarcinoma and 29 were diagnosed to be clear cell adenocarcinoma. In the tumor specimens obtained by surgical resection, the expression levels of the GPR30, EGFR, ER $\alpha$ and ER $\beta$ proteins were evaluated. A representative example of the immunostaining analysis is shown in Figure 1. The expression of GPR30 and EGFR was detected mainly in the cytoplasm, and the $E R \alpha$ and $E R \beta$ expression was detected mainly in the nuclei of the tumor specimens.

We also examined the relationships between the clinicopathological factors and the immunohistochemical staining patterns, the results of which are shown in Tables 2 and 3. There were no significant associations between the GPR30 expression and the patient age or menstrual status. However, the GPR30 expression 
Table 1 Characteristics of borderline malignancy and epithelial ovarian cancer cases

\begin{tabular}{ll}
\hline Variables & Number of patients (\%) \\
\hline & $\mathrm{N}=162$ \\
Age (years) & $54.1 \pm 12.5$ \\
Postmenopausal & 96 \\
Premenopausal & 66 \\
BMI & $22.0 \pm 3.4$ \\
Histology Borderline malignancy & $10(6.1 \%)$ \\
Serous adenocarcinoma & $61(37.6 \%)$ \\
Endometrioid adenocarcinoma & $30(18.5 \%)$ \\
Mucinous adenocarcinoma & $19(11.7 \%)$ \\
Clear cell adenocarcinoma & $29(17.9 \%)$ \\
Other & $13(8.0 \%)$ \\
FIGO stage I & $49(30.2 \%)$ \\
$\quad$ II & $14(8.6 \%)$ \\
$\quad$ IV & $77(47.5 \%)$ \\
\hline
\end{tabular}

correlated with the mean body mass index (BMI in $\left.\mathrm{kg} / \mathrm{cm}^{2}\right)$ $(\mathrm{p}<0.04)$. The GPR30 expression in ovarian carcinomas was significantly higher than that in borderline malignancies $(\mathrm{p}=0.0016)$. Interestingly, the GPR30 expression was significantly related to the histological subtype $(\mathrm{p}<0.001)$. GPR30 expression was observed in $75.4 \%$ (46/61) of serous adenocarcinomas, 83.3\% (25/30) of endometrioid adenocarcinomas and 73.7\% (14/19) of mucinous adenocarcinomas, while $20.7 \%(6 / 29)$ of clear cell carcinomas were observed to express the protein.

No significant associations between the EGFR, ER $\alpha$ and ER $\beta$ expression and the patient age, menstrual status or BMI were observed. The EGFR expression level in ovarian carcinomas was significantly higher than that in borderline malignancies $(\mathrm{p}=0.012)$, although the ER $\alpha$ and ER $\beta$ expression in ovarian carcinomas was not significantly different from that in borderline malignancies. Interestingly, the ER $\alpha$ expression levels were also significantly related to the histological subtype $(\mathrm{p}=0.004)$.

\section{Prognostic impact of GPR30, EGFR, ERa and ER $\beta$ expression in ovarian carcinoma}

We also examined the relationship between the staining intensity of various markers and patient survival. The median survival time for all patients was 5.2 years. Recent studies have shown that GPR30 is expressed in a variety of estrogen-responsive cancer cells, and that it activates the epidermal growth factor receptor (EGFR) transduction pathway in various malignancies $[19,20,27$ 29]. We therefore examined the GPR30-related status, as represented by the co-expression of GPR30 and the EGFR, and its relationship to the patients' survival. A high tumor co-expression of GPR30 and EGFR was significantly associated with a poorer progression-free
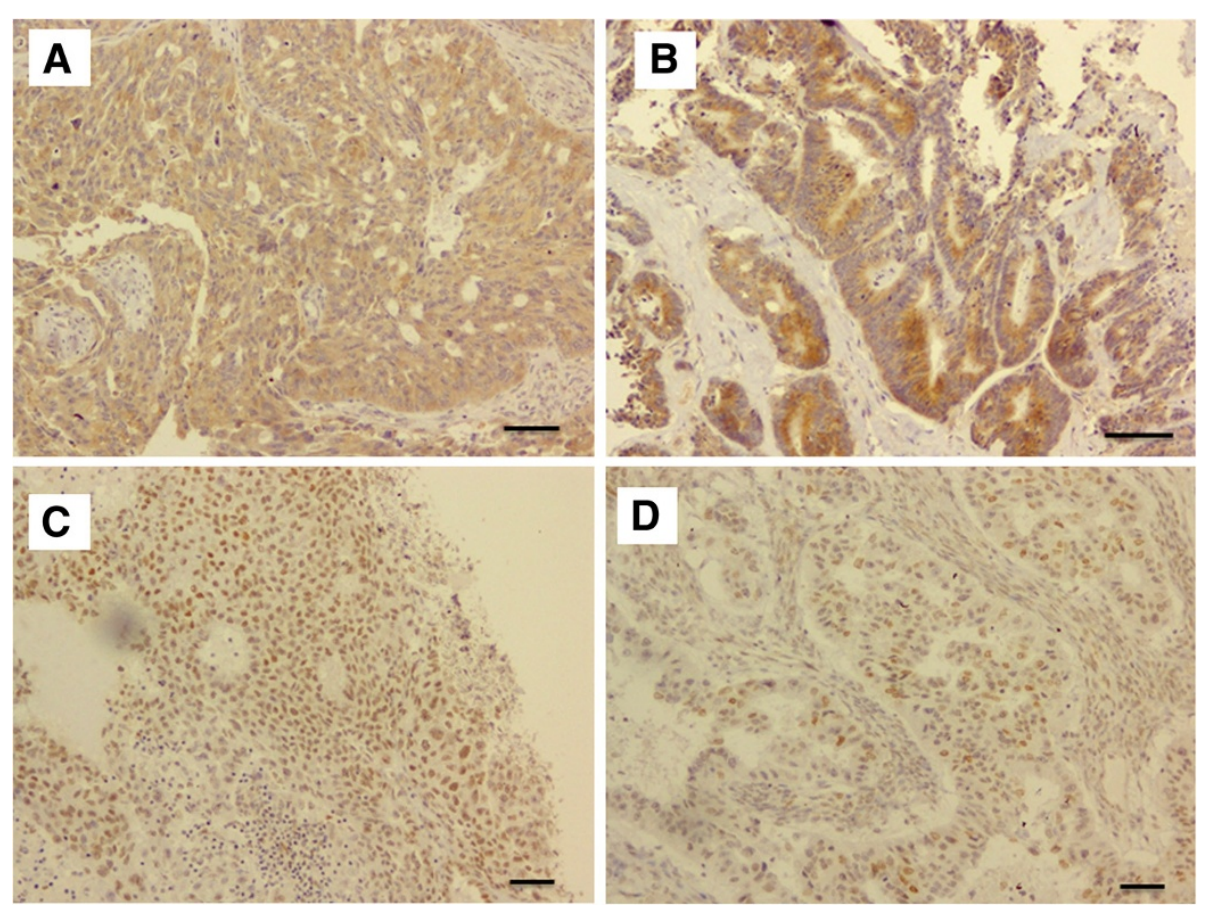

Figure 1 Representative examples of immunohistochemically-stained sections. Representative examples of immunohistochemically-stained sections from tumor specimens that were positive for GPR30 (A), EGFR (B), ERa (C) and ERß (D). Scale bars represent $100 \mu \mathrm{m}$. 
Table 2 Correlations between GPR30 and EGFR expression and clinicopathological factors

\begin{tabular}{|c|c|c|c|c|c|c|}
\hline \multirow[t]{2}{*}{ Variables } & \multicolumn{2}{|c|}{ Expression of GPR30 } & \multirow[t]{2}{*}{$p$ value } & \multicolumn{2}{|c|}{ Expression of EGFR } & \multirow[t]{2}{*}{$\mathrm{p}$ value } \\
\hline & Positive & Negative & & Positive & Negative & \\
\hline Age & $54.0 \pm 12.7$ & $54.3 \pm 12.2$ & 0.49 & $54.3 \pm 11.9$ & $53.9 \pm 13.5$ & 0.84 \\
\hline Premenopausal & $40(60.6 \%)$ & $26(39.4 \%)$ & 0.80 & $27(40.9 \%)$ & $39(59.1 \%)$ & 0.39 \\
\hline Postmenopausal & $60(60.6 \%)$ & $36(39.4 \%)$ & & $33(33.3 \%)$ & $63(66.7 \%)$ & \\
\hline BMl & $21.5 \pm 2.7$ & $22.6 \pm 4.2$ & 0.04 & $21.4 \pm 3.6$ & $22.2 \pm 2.8$ & 0.11 \\
\hline Borderline malignancy & $1(10.0 \%)$ & $9(90.0 \%)$ & 0.0016 & $0(0 \%)$ & $10(100 \%)$ & 0.012 \\
\hline FIGO stage I & $26(66.7 \%)$ & $13(33.3 \%)$ & 0.31 & $13(33.3 \%)$ & $26(66.7 \%)$ & 0.77 \\
\hline$\|$ & $11(78.6 \%)$ & $3(21.4 \%)$ & & $7(50.0 \%)$ & $7(50.0 \%)$ & \\
\hline III & $47(61.3 \%)$ & $30(38.7 \%)$ & & $32(41.6 \%)$ & $45(58.4 \%)$ & \\
\hline IV & $15(68.2 \%)$ & $7(31.8 \%)$ & & $8(36.4 \%)$ & $14(63.6 \%)$ & \\
\hline \multicolumn{7}{|l|}{ Histology } \\
\hline Borderline malignancy & $1(10.0 \%)$ & $9(90.0 \%)$ & 0.0016 & $0(0 \%)$ & $10(100 \%)$ & 0.012 \\
\hline Serous adenocarcinoma & $46(75.4 \%)$ & $15(24.6 \%)$ & $<0.001$ & $24(39.3 \%)$ & $37(60.7 \%)$ & 0.42 \\
\hline Endometrioid adenocarcinoma & $25(83.3 \%)$ & $5(16.7 \%)$ & & $11(36.7 \%)$ & $19(63.3 \%)$ & \\
\hline Mucinous adenocarcinoma & $14(73.7 \%)$ & $5(26.3 \%)$ & & $8(42.1 \%)$ & $11(57.9 \%)$ & \\
\hline Clear cell adenocarcinoma & $6(20.7 \%)$ & $23(79.3 \%)$ & & $14(48.3 \%)$ & $15(51.7 \%)$ & \\
\hline Others & $8(61.5 \%)$ & $5(38.5 \%)$ & & $3(23.1 \%)$ & $10(76.9 \%)$ & \\
\hline Recurrence & & & 0.30 & & & 0.31 \\
\hline$\leq 6 \mathrm{M}$ & $13(68.4 \%)$ & $6(31.6 \%)$ & & $9(47.4 \%)$ & $10(52.6 \%)$ & \\
\hline$>6 \mathrm{M}$ & $43(67.2 \%)$ & $21(32.8 \%)$ & & $20(31.3 \%)$ & $44(68.7 \%)$ & \\
\hline No recurrence & $44(55.7 \%)$ & $35(44.3 \%)$ & & $31(39.2 \%)$ & $48(60.8 \%)$ & \\
\hline 5-year survival & & & 0.56 & & & 0.86 \\
\hline Alive & $63(61.8 \%)$ & 39 (38.2\%) & & 35 (34.3\%) & $67(65.7 \%)$ & \\
\hline Dead & $37(61.7 \%)$ & $23(38.3 \%)$ & & $25(41.7 \%)$ & $35(58.3 \%)$ & \\
\hline
\end{tabular}

survival $(\mathrm{p}<0.001)$ (Figure 2). However, the individual GPR30 and EGFR expression levels, and the ER $\alpha$ and ER $\beta$ expression levels, were not significantly related to the survival.

\section{G1 stimulates the proliferation of Caov-3 ovarian carcinoma cells}

In recent studies, GPR30 was reported to regulate the GPR30-dependent activation of MAPK-ERK1/2 via EGFR transactivation in breast cancer and endometrial cancer $[17,20]$. However, it is unclear whether GPR30mediated Akt activation via EGFR transactivation occurs in ovarian cancer. To assess this possibility, we first evaluated the ability of G1, a selective GPR30 agonist, to activate a transiently transfected GPR30 gene in an ovarian cancer cell line (Caov-3 cells). The mRNA expression of GPR30 in Caov-3 cells was evaluated by semi quantitative RT-PCR (Figure 3A). The mRNA expression of GPR30 in Caov-3 cells that were not transfected with the GPR30 gene was significantly lower than that in Caov-3 cells transfected with the GPR30 gene (Figure 3A). The proliferation of the Caov-3 cells was examined using the MTS assay. As shown in Figure 3, a concentration of $100 \mathrm{nM}$ of G1 enhanced the proliferation of Caov-3 cells for $48 \mathrm{~h}$ in culture $((\mathrm{p}=0.0016)$, and $100 \mathrm{nM}$ of G15, which is a selective GPR30 antagonist, inhibited the G1-induced proliferation of the Caov-3 cells (Figure 3B) (Western blotting analysis; Additional file 1: Figure S3).

\section{GPR30 signaling initiates EGFR-Akt signaling in ovarian cancer cells}

Next, we ascertained that in Caov-3 cells, rapid phosphorylation of the EGFR and Akt were induced by G1 via Src using a Western blot analysis. The mRNA expression of GPR30 in the Caov-3 cells was confirmed by semiquantitative RT-PCR (Figure 3A). As shown in Figure $4 \mathrm{~A}$, the phosphorylation of the EGFR could be significantly enhanced by the addition of $100 \mathrm{nM}$ G1 $(\mathrm{p}<0.01)$, to a similar extant as was observed using EGF. The phosphorylation of Akt could also be significantly enhanced by $100 \mathrm{nM}$ of G1 ( $<<0.01)$ or EGF, and could be inhibited by PP1, which is a Src family kinase inhibitor (Figure 4B, A2780 cells; Additional file 2: Figure S1, RMG-1 cells; Additional file 3: Figure S2). 
Table 3 Correlations between the clinicopathological factors and estrogen receptors (ERa, ERb)

\begin{tabular}{|c|c|c|c|c|c|c|}
\hline \multirow[t]{2}{*}{ Variables } & \multicolumn{2}{|c|}{ Expression of ERa } & \multirow[t]{2}{*}{$p$ value } & \multicolumn{2}{|c|}{ Expression of ER $\beta$} & \multirow[t]{2}{*}{$\mathrm{p}$ value } \\
\hline & Positive & Negative & & Positive & Negative & \\
\hline Age & $55.9 \pm 13.1$ & $52.6 \pm 13.1$ & 0.12 & $55.8 \pm 12.3$ & $53.6 \pm 11.9$ & 0.37 \\
\hline Premenopausal & $24(36.4 \%)$ & $42(63.6 \%)$ & 0.24 & $16(24.2 \%)$ & $50(75.8 \%)$ & 0.85 \\
\hline Postmenopausal & $41(42.7 \%)$ & $55(57.3 \%)$ & & $20(20.8 \%)$ & $76(79.2 \%)$ & \\
\hline BMI & $22.3 \pm 2.5$ & $21.7 \pm 2.6$ & 0.24 & $21.7 \pm 4.5$ & $22.0 \pm 2.9$ & 0.75 \\
\hline Borderline malignancy & $5(50.0 \%)$ & $5(50.0 \%)$ & 0.72 & $6(60.0 \%)$ & $4(40.0 \%)$ & 0.08 \\
\hline FIGO stage I & $10(25.6 \%)$ & $29(74.4 \%)$ & 0.99 & $14(35.9 \%)$ & $25(64.1 \%)$ & 0.06 \\
\hline$\|$ & $9(64.3 \%)$ & $5(35.7 \%)$ & & $2(14.3 \%)$ & $12(85.7 \%)$ & \\
\hline III & $34(44.2 \%)$ & $43(55.8 \%)$ & & $14(18.2 \%)$ & $63(81.8 \%)$ & \\
\hline IV & $7(31.8 \%)$ & $15(68.2 \%)$ & & $0(0 \%)$ & $22(100 \%)$ & \\
\hline \multicolumn{7}{|l|}{ Histology } \\
\hline Borderline malignancy & $5(50.0 \%)$ & $5(50.0 \%)$ & 0.72 & $6(60.0 \%)$ & $4(40.0 \%)$ & 0.08 \\
\hline Serous adenocarcinoma & $32(52.5 \%)$ & $29(47.5 \%)$ & 0.004 & $11(18.0 \%)$ & $50(82.0 \%)$ & 0.14 \\
\hline Endometrioid adenocarcinoma & $16(53.3 \%)$ & $14(46.7 \%)$ & & $4(13.8 \%)$ & $26(86.2 \%)$ & \\
\hline Mucinous adenocarcinoma & $5(26.3 \%)$ & $14(73.7 \%)$ & & $8(42.1 \%)$ & $11(57.9 \%)$ & \\
\hline Clear cell adenocarcinoma & $3(10.3 \%)$ & $26(89.7 \%)$ & & $6(20.7 \%)$ & $23(79.3 \%)$ & \\
\hline Others & $4(30.8 \%)$ & $9(69.2 \%)$ & & $1(7.7 \%)$ & $12(92.3 \%)$ & \\
\hline Recurrence & & & 0.14 & & & 0.06 \\
\hline$\leq 6 \mathrm{M}$ & $8(42.1 \%)$ & $11(57.9 \%)$ & & $4(21.1 \%)$ & $15(78.9 \%)$ & \\
\hline$>6 \mathrm{M}$ & $31(48.4 \%)$ & $33(51.6 \%)$ & & $10(15.6 \%)$ & $54(84.4 \%)$ & \\
\hline No recurrence & $26(32.9 \%)$ & $53(67.1 \%)$ & & $22(27.8 \%)$ & $57(72.2 \%)$ & \\
\hline 5-year survival & & & 0.47 & & & 0.06 \\
\hline Alive & $41(40.2 \%)$ & $61(59.8 \%)$ & & $26(25.4 \%)$ & $76(74.6 \%)$ & \\
\hline Dead & $24(40.0 \%)$ & $36(60.0 \%)$ & & $10(16.7 \%)$ & $50(83.3 \%)$ & \\
\hline
\end{tabular}
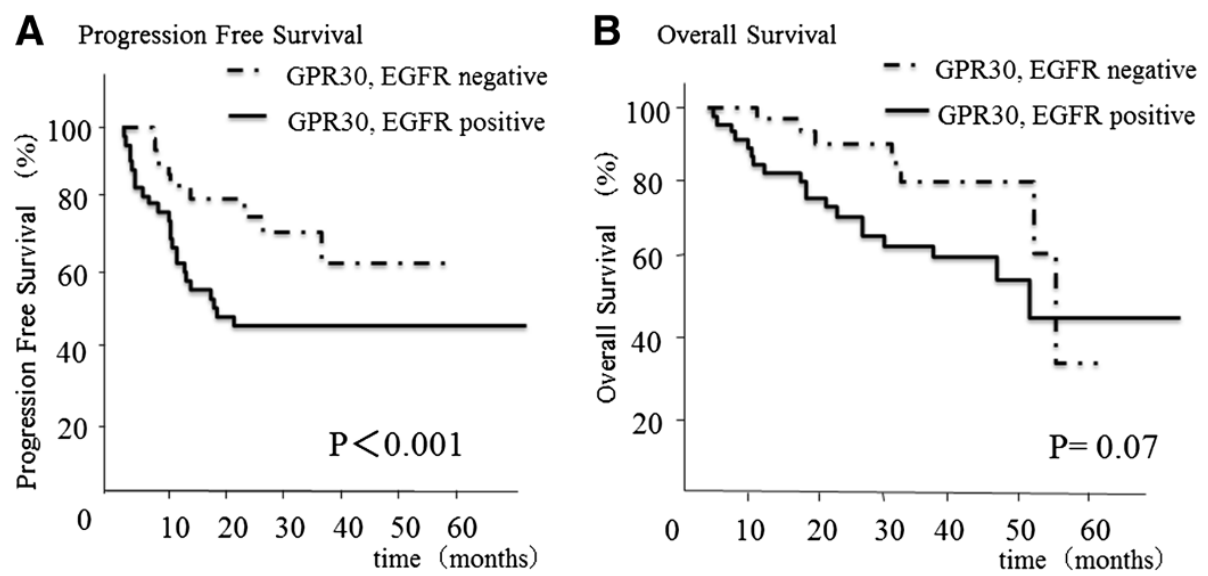

Figure 2 Correlation of the co-expression of GPR30 and EGFR with the progression-free survival or overall survival. (A) A high level of tumor co-expression of GPR30 and EGFR was significantly associated with a poorer progression-free survival $(p<0.001)$. (B) There was no significant relationship, but there was a tendency for there to be a correlation between the overall survival and the co-expression of GPR30 and EGFR (P=0.07). 


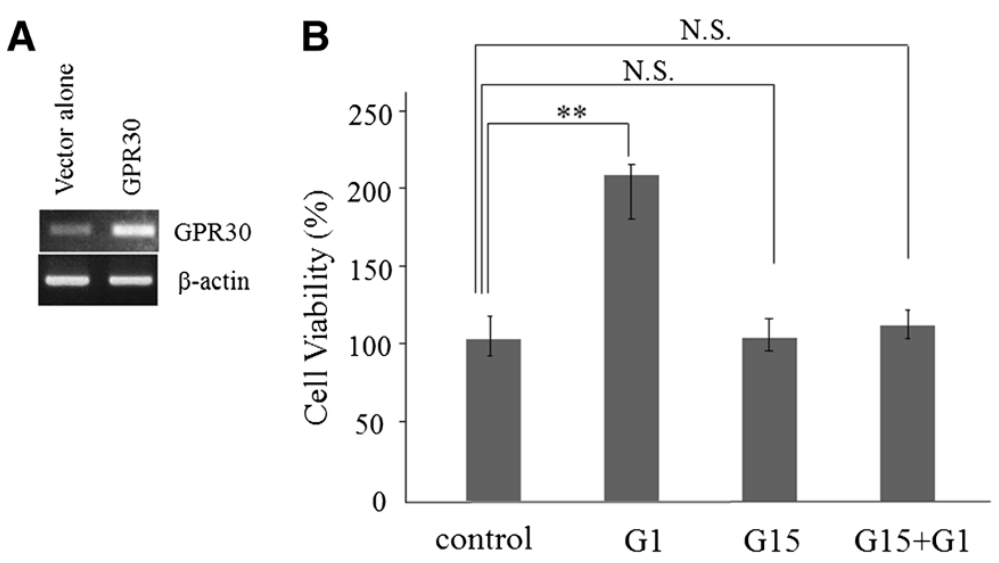

Figure 3 The proliferation of the Caov-3 cells following stimulation with G1, a selective GPR30 agonist, and G15, a selective GPR30 antagonist. Caov-3 cells were transfected with the pcDNA3.1 vector (Vector alone) or pcDNA3.1-GPR30 (GPR30). (A) The mRNA expression of GPR30 in Caov-3 cells was confirmed by semiquantitative RT-PCR. (B) The proliferation of the Ca-ov3 cells transfected with pcDNA3.1-GPR30 was examined using the MTS assay. The Caov-3 cells transfected with pcDNA3.1-GPR30 were treated with G1 (100 nM), G15 (100 nM), or both G1 and G15 (100 nM each) for 48 hours. The cell number is expressed as a percentage of the control (100\%) which Caov-3 cells transfected with pCDNA3.1-GPR30. The values shown represent the means \pm SE of three independent experiments performed in quadruplicate in three different passages of the cell lines. Significant differences are shown by asterisks: ${ }^{* *}, p<0.01$.

\section{Discussion}

The current study revealed that the novel estrogenresponsive receptor, GPR30, is preferentially active in ovarian cancer, similar to breast, endometrial, prostate and lung carcinomas. Moreover, we also showed that GPR30 was expressed at higher levels and was more frequently observed in ovarian cancer than in borderline malignant tumors. These data are consistent with a previous report [35].

Estrogens stimulate the proliferation of ovarian cancer cell lines and normal ovarian surface epithelial cells in culture $[36,37]$. However, the ER is present in only $60 \%$ of ovarian cancers [13]. We demonstrated that GPR30 overexpression was not associated with the ER expression. These data suggest the presence of a complicated relationship between GPR30 and the ER. Although GPR30 is widely expressed in cancer cell lines and primary malignant tumors of the breast, endometrium, prostate and lungs $[16,17]$, the role of GPR30 in ovarian carcinoma was unclear. Albanito et al. reported that GPR30 was involved in the proliferation of ovarian cancer cells [38]. The signaling pathways employed by GPR30 activation have not yet been fully elucidated.

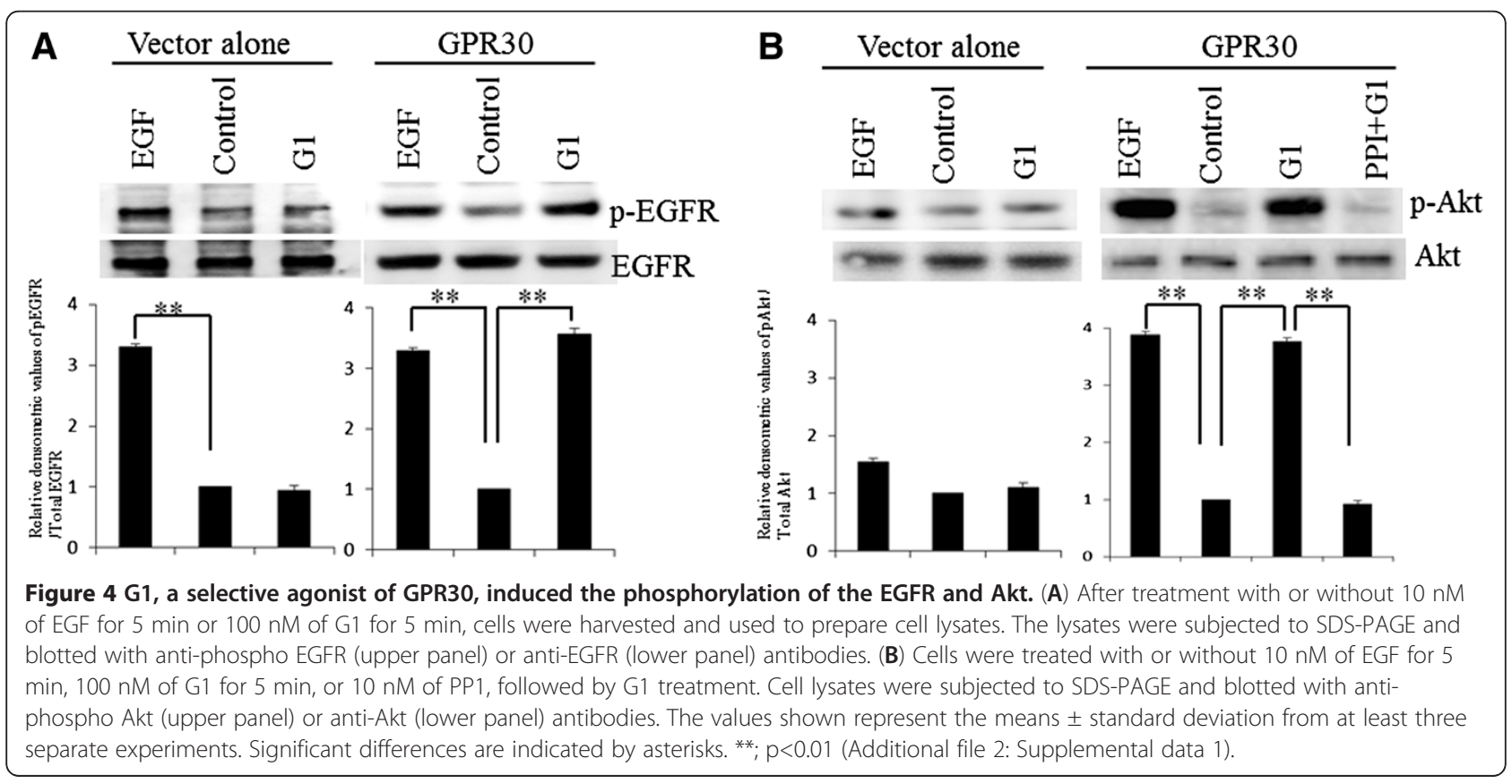


Figaro et al. showed that GPR30 regulated the activation of MAPK-ERK1/2 via EGFR transactivation in ER-negative breast cancer cell lines [20]. This suggests that GPR30 is the sole receptor responsive to estrogen that leads to EGFR transactivation in ER-negative breast cancer. The EGFR is reported to be present in 33-75\% [30] of ovarian cancers, and has been implicated in both the growth and progression of this disease [31]. In the present study, we proved that G1, a selective GPR30 agonist, induces the proliferation of Caov-3 ovarian cancer cells, and that G15, a selective GPR30 antagonist, inhibits the G1-induced proliferation of Caov-3 cells. Moreover, G1, like EGF, significantly enhanced the activation of both the EGFR and Akt signaling pathways, and the activation of these pathways was inhibited by PP1, a Src family kinase inhibitor. This might suggest that GPR30 is involved in a signaling cascade that is transduced via the EGFR, which leads to a poor prognosis for ovarian cancer, since the phosphorylation of Akt via the EGFR is key to the development and/ or progression of ovarian cancer [39].

In the present study, we demonstrated that the coexpression of GPR30 and the EGFR was associated with a poorer progression-free survival in patients with ovarian cancer, although we could not confirm the presence of a correlation between GPR30 and the survival of ovarian cancer patients, as was the case in a previous report [40]. Our clinical results support the idea that GPR30 regulates an EGFR cascade, which is closely related to cancer cell growth and the survival of ovarian cancer patients. We have previously reported that the phosphorylation of Akt leads to increased cell survival and is associated with platinum resistance due to its anti-apoptotic effects in ovarian cancer cells [34], and that it was associated with a poor overall survival in ovarian carcinoma patients [33]. In the current study, we also revealed that the cell proliferation in ovarian cancer were dependent on GPR30.

Of note, we also showed that the expression of GPR30 in clear cell carcinoma was significantly lower than that in other types of ovarian cancer. Clear cell adenocarcinoma is well known to have the worst prognosis of the various subtypes of ovarian cancer because of its resistance to chemotherapy, which has been attributed to a slow cell cycle [41]. Clear cell ovarian tumors do not express estrogen or progesterone receptors, and endometriosis that transforms into clear-cell ovarian cancer can become hormone independent during the transformation process [42]. Pandeet al. reported that GPR30 signaling induces proliferation and promotes cell cycle progression [23]. Our current results showed that there was low expression of not only ER $\alpha$, but also GPR30, in clear cell adenocarcinoma, which means that clear cell adenocarcinoma is likely to have slow proliferation or slow cell cycling. This study is the first report to show that the expression of GPR30 is associated with a specific histological subtype. Our findings may imply that the poorer prognosis of clear cell adenocarcinoma (which is related to its resistance to chemotherapy) correlates with low GPR30 expression, and might be associated with a slow cell cycle.

\section{Conclusions}

We herein demonstrated that the co-expression of GPR30 and EGFR was associated with a poorer progression free survival in ovarian cancer patients, and that GPR30 activates the phosphorylation of Akt via the EGFR in ovarian cancer cells. These lines of evidence reinforce our speculation that GPR30 plays an important role in ovarian cancer, other than clear cell carcinoma. The small sample size is a limitation of the present study. Therefore, further examinations will be needed to fully elucidate the functions and role(s) of GPR30. However, these studies can lead to a deeper understanding of tumorigenesis and may provide improved treatments for ovarian cancer. We believe that the regulation of GPR30 may be a potentially useful new therapeutic target in ovarian cancer.

\section{Additional files}

Additional file 1: Figure S3. 17ß-estradiol induced the phosphorylation of the EGFR and Akt in GPR30 transfected cells.

Additional file 2: Figure S1. G1 induced the phosphorylation of the EGFR and Akt in A2780 cells.

Additional file 3: Figure S2. G1 induced the phosphorylation of the EGFR and Akt in RMG- cells.

\section{Abbreviations}

GPR 30: G protein-coupled receptor 30; ERa: Estrogen receptor a; ERß: Estrogen receptor $\beta$; EGFR: Epidermal growth factor receptor; ERES: Estrogen-responsive elements; E2: 17-beta-estragiol; PLC: Phospholipase C; PI3K: Phosphatidylinositol-3 kinase; ERK: Extracellular signal-related kinase; BMI: Body mass index.

\section{Competing interests}

The authors declare that they have no competing interests.

\section{Authors' contributions}

SF carried out the evaluation of the immunohistochemical staining, the Western blot analysis, part of the gene expression experiments, and the statistical analysis. YT participated in conception and design of the study, supplied the TMA, and drafted the manuscript. HK, MT, SY and YT

participated in the design of the study and the analysis of the clinical data. $T, S T, H S$, and MK supplied the TMA material and evaluated the histology of the tumor samples and the immunohistochemical staining. AT carried out the Western blot analysis and part of the gene expression experiments, and cultured the cells. YY and MO contributed methodological knowhow and participated in the design of the study. All authors read and approved the final manuscript.

\section{Acknowledgments}

This work was supported by a Grant-in-Aid for Scientific Research on Priority Areas, No.22591869 (to Y. T.) from the Ministry of Education, Culture, Sports, Science and Technology of Japan.

Received: 12 August 2012 Accepted: 9 November 2012

Published: 19 November 2012 


\section{References}

1. Jemal A, Siegel R, Xu J, Ward E: Cancer statistics, 2010. CA Cancer J Clin 2010, 60:277-300.

2. Bai W, Oliveros-Saunders B, Wang Q, Acevedo-Duncan ME, Nicosia SV: Estrogen stimulation of ovarian surface epithelial cell proliferation. In Vitro Cell Dev Biol Anim 2000, 36:657-666.

3. Rodriguez C, Patel AV, Calle EE, Jacob EJ, Thun MJ: Estrogen replacement therapy and ovarian cancer mortality in a large prospective study of US women. JAMA 2001, 285:1460-1465.

4. Riman T, Dickman PW, Nilsson S, Correia N, Nordlinder H, Magnusson CM, Weiderpass E, Persson IR: Hormone replacement therapy and the risk of invasive epithelial ovarian cancer in Swedish woman. J Natl Cancer Inst 2002, 94:497-504.

5. Lacey JV Jr, Mink PJ, Lubin JH, Sherman ME, Troisi R, Hartge P, Schatzkin A, Schairer C: Menopausal hormone replacement therapy and risk of ovarian cancer. JAMA 2002, 288:334-341.

6. Hall JM, Couse JF, Korach KS: The multifaceted mechanisms of estradiol and estrogen receptor signaling. J Biol Chem 2001, 276:36869-36872

7. Thomas P: Chemical interference with genomic and nongenomic actions of steroids in fishes: role of receptor binding. Mar Environ Res 2000, 50:127-134.

8. Hiller SG, Anderson RA, Williams AR, Tetsuka M: Expression of oestrogen receptor alpha and beta in cultured human ovarian surface epithelial cells. Mol Hum Reprod 1998, 4:811-815.

9. Pujol P, Rey JM, Nirde P, Roger P, Gastaldi M, Laffargue F, Rochefort $H_{\text {, }}$ Maudelonde T: Differential expression of estrogen receptor-alpha and beta messenger RNAs as a potential marker of ovarian carcinogenesis. Cancer Res 1998, 58:5367-5373.

10. Brandenberger AW, Tee MK, Jaffe RB: Estrogen receptor alpha (ER-alpha) and beta (ER-beta) mRNAs in normal ovary, ovarian serous cystadenocarcinoma and ovarian cancer cell lines: down-regulation of ER-beta in neoplastic tissues. J Clin Endocrinol Metab 1998, 83:1025-1028

11. Kuiper GG, Gustafsson JA: The novel estrogen receptor-beta subtype: potential role in the cell- and promoter-specific actions of estrogens and anti-estrogens. FEBS Lett 1997, 410:87-90.

12. Rutherford T, Brown WD, Sapi E, Aschkenazi S, Monoz A, Mor G: Absence of estrogen receptor-beta expression in metastatic ovarian cancer. Obstet Gynecol 2000, 96:417-421.

13. Rao BR, Slotman BJ: Endocrine factors in common epithelial ovarian cancer. Endocr Rev 1991, 12:14-26.

14. Hatch KD, Beecham JB, Blessing JA, Creasman WT: Responsiveness of patients with advanced ovarian carcinoma to tamoxifen. A Gynecologic Oncology Group study of second-line therapy in 105 patients. Cancer 1991, 68:269-271.

15. Perez-Gracia JL, Carrasco EM: Tamoxifen therapy for ovarian cancer in the adjuvant and advanced settings: systematic review of the literature and implications for future research. Gynecol Oncol 2002, 84:201-209.

16. Prossnitz ER, Barton M: The G-protein-coupled estrogen receptor GPER in health and disease. Nat Rev Endocrinol 2011, 7:715-726.

17. Smith HO, Leslie KK, Singh M, Qualls CR, Revankar CM, Joste NE, Prossnitz ER: GPR30: a novel indicator of poor survival for endometrial carcinoma. Am J Obstet Gynecol 2007, 196(4):386 e381-386 e389. discussion 386 e389-11.

18. Albanito L, Madeo A, Lappano R, Vivacqua A, Rago V, Carpino A, Oprea TI, Prossnitz ER, Musti AM, Andò S, Maggiolini M: G protein-coupled receptor 30 (GPR30) mediates gene expression changes and growth response to 17beta-estradiol and selective GPR30 ligand G-1 in ovarian cancer cells. Cancer Res 2007, 67:1859-1866.

19. Maggiolini M, Vivacqua A, Fasanella G, Recchia AG, Sisci D, Pezzi V, Montanaro D, Musti AM, Picard D, Andò S: The G protein-coupled receptor GPR30 mediates c-fos up-regulation by 17 beta-estradiol and phytoestrogens in breast cancer cells. J Biol Chem 2004, 279:27008-27016.

20. Filardo EJ, Quinn JA, Bland Kl, Frackelton AR Jr: Estrogen-induced activation of Erk-1 and Erk-2 requires the $\mathrm{G}$ protein-coupled receptor homolog, GPR30, and ocurrs via trans-activation of the epidermal growth factor receptor through release of HB-EGF. Mol Endocrinol 2000, 14:1649-1660

21. He $Y Y, C a i$, Yang $Y X$, Liu XL, Wan XP: Estrogenic G protein-coupled receptor 30 signaling is involved in regulation of endometrial carcinoma by promoting proliferation, invasion potential, and interleukin- 6 secretion via the MEK/ERK mitogen-activated protein kinase pathway. Cancer Sci 2009, 100:1051-1061

22. Filardo EJ, Graeber $C T$, Quinn JA, Resnick MB, Giri D, DeLellis RA, Steinhoff MM, Sabo E: Distribution of GPR30, a seven membrane-spanning estrogen receptor, in primary breast cancer and its association with clinicopathologic determinants of tumor progression. Clin Cancer Res 2006, 12:6359-6366.

23. Pandey DP, Lappano R, Albanito L, Madeo A, Maggiolini M, Picard D: Estrogenic GPR30 signalling induces proliferation and migration of breast cancer cells through CTGF. EMBO J 2009, 28:523-532.

24. Kleuser B, Malek D, Gust R, Pertz HH, Potteck H: 17-Beta-estradiol inhibits transforming growth factor-beta signaling and function in breast cancer cells via activation of extracellular signal-regulated kinase through the G protein-coupled receptor 30. Mol Pharmacol 2008, 74:1533-1543

25. Filardo EJ: Epidermal growth factor receptor (EGFR) transactivation by estrogen via the G-protein-coupled receptor, GPR30: a novel signaling pathway with potential significance for breast cancer. J Steroid Biochem Mol Biol 2002, 80:231-238.

26. Arias-Pulido $H$, Royce $M$, Gong $Y$, Joste $N$, Lomo L, Lee $S$ J, Chaher $N$, Verschraegen C, Lara J, Prossnitz ER, Cristofanilli M: GPR30 and estrogen receptor expression: new insights into hormone dependence of inflammatory breast cancer. Breast Cancer Res Treat 2010, 123:51-58.

27. Bologa CG, Revankar CM, Young SM, Edwards BS, Arterburn JB, Kiselyov AS, Parker MA, Tkachenko SE, Savchuck NP, Sklar LA, Oprea TI, Prossnitz ER: Virtual and biomolecular screening converge on a selective agonist for GPR30. Nat Chem Biol 2006, 2:207-212.

28. Thomas $P$, Pang $Y$, Filardo EJ, Dong J: Identity of an estrogen membrane receptor coupled to a $\mathrm{G}$ protein in human breast cancer cells. Endocrinology 2005, 146:624-632.

29. Vivacqua A, Bonofiglio D, Recchia AG, Musti AM, Picard D, Andò S, Maggiolini M: The G protein-coupled receptor GPR30 mediates the proliferative effects induced by 17 beta-estradiol and hydroxytamoxifen in endometrial cancer cells. Mol Endocrinol 2006, 20:631-646.

30. Berchuck A, Rodriguez GC, Kamel A, Dodge RK, Soper JT, Clarke-Pearson DL, et al: Epidermal growth factor receptor expression in normal ovarian epithelium and ovarian cancer. I. Correlation of receptor expression with prognostic factors in patients with ovarian cancer. Am J Obstet Gynecol 1991, 164:669-674

31. Psyrri A, Kassar M, Yu Z, Bamias A, Weinberger PM, Markakis S, Kowalski D, Camp RL, Rimm DL, Dimopoulos MA: Effect of epidermal growth factor receptor expression level on survival in patients with epithelial ovarian cancer. Clin Cancer Res 2005, 11:8637-8643.

32. Vivanco I, Sawyers CL: The phosphatidylinositol 3-Kinase AKT pathway in human cancer. Nat Rev Cancer 2002, 2:489-501.

33. Tanaka Y, Terai $Y$, Tanabe A, Sasaki H, Sekijima T, Fujiwara S, Yamashita $Y$, Kanemura M, Ueda M, Sugita M, Franklin WA, Ohmichi M: Prognostic effect of epidermal growth factor receptor gene mutations and the aberrant phosphorylation of Akt and ERK in ovarian cancer. Cancer Biol Ther 2011, 11:50-57.

34. Tsunetoh S, Terai Y, Sasaki H, Tanabe A, Tanaka Y, Sekijima T, Fujioka S, Kawaguchi H, Kanemura M, Yamashita Y, Ohmichi M: Topotecan as a molecular targeting agent which blocks the Akt and VEGF cascade in platinum-resistant ovarian cancers. Cancer Biol Ther 2010, 10:1137-1146.

35. Smith HO, Arias-Pulido H, Kuo DY, Howard T, Qualls CR, Lee SJ, Verschraegen CF, Hathaway HJ, Joste NE, Prossnitz ER: GPR30 predicts poor survival for ovarian cancer. Gynecol Oncol 2009, 114:465-471.

36. Syed V, Ulinski G, Mok SC, Yiu GK, Ho SM: Expression of gonadotropin receptor and growth responses to key reproductive hormones in normal and malignant human ovarian surface epithelial cells. Cancer Res 2001 61:6768-6776

37. Nash JD, Ozols RF, Smyth JF, Hamilton TC: Estrogen and anti-estrogen effects on the growth of human epithelial ovarian cancer in vitro. Obstet Gynecol 1989, 73:1009-1016.

38. Albanito L, Lappano R, Madeo A, Chimento A, Prossnitz ER, Cappello AR, Dolce V, Abonante S, Pezzi V, Maggiolini M: G-protein-coupled receptor 30 and estrogen receptor-alpha are involved in the proliferative effects induced by atrazine in ovarian cancer cells. Environ Health Perspect 2008, 116:1648-1655. 
39. Guo RX, Qiao YH, Zhou Y, Li LX, Shi HR, Chen KS: Increased staining for phosphorylated AKT and nuclear factor-kappaB p65 and their relationship with prognosis in epithelial ovarian cancer. Pathol Int 2008, 58:749-756.

40. Kolkova Z, Casslen V, Henic E, Ahmadi S, Ehinger A, Jirstrom K, Casslen B: The G protein-coupled estrogen receptor 1 (GPER/GPR30) dose not predict survival in patients with ovarian cancer. J Ovarian Res 2012, 5:9.

41. Itamochi H, Yoshida T, Walker CL, Bartholomeusz C, Aoki D, Ishihara H, Suzuki N, Kigawa J, Terakawa N, Ueno NT: Novel mechanism of reduced proliferation in ovarian clear cell carcinoma cells: cytoplasmic sequestration of CDK2 by p27. Gynecol Oncol 2011, 122:641-647.

42. Gilks CB: Molecular abnormalities in ovarian cancer subtypes other than high-grade serous carcinoma. J Oncol 2010, Article ID 740968.

doi:10.1186/1757-2215-5-35

Cite this article as: Fujiwara et al:: GPR30 regulates the EGFR-Akt

cascade and predicts lower survival in patients with ovarian cancer. Journal of Ovarian Research 2012 5:35.

\section{Submit your next manuscript to BioMed Central and take full advantage of:}

- Convenient online submission

- Thorough peer review

- No space constraints or color figure charges

- Immediate publication on acceptance

- Inclusion in PubMed, CAS, Scopus and Google Scholar

- Research which is freely available for redistribution 